\title{
Performance Evaluation of Adaptive Tabu Search Algorithm Optimized Sinusoidal Fryze Voltage Control based Hybrid Series Active Power Filter
}

\author{
Saifullah Khalid ${ }^{1}$, Niraj Kumar ${ }^{2}$, and V. M. Mishra ${ }^{3}$ \\ ${ }^{1}$ UIET, CSJM University, ${ }^{2}$ Kanpur, INDIA, ${ }^{3}$ GBP Engineering College, INDIA
}

\begin{abstract}
A novel hybrid series active power filter to eliminate harmonics and compensate reactive power is presented and analyzed. The proposed active compensation technique is based in a hybrid series active filter using adaptive tabu search algorithm in the conventional Sinusoidal Fryze voltage control technique. The paper analyzes the proposed hybrid series active power filter when connected with load of 3-phase diode bridge rectifier with R-L branch directly. This paper intends to show the improvement between the performance of conventional scheme and ATS-optimized scheme. Simulation results obtained using MATLAB/Simulink confirm the viability of the proposed compensation technique.
\end{abstract}

Keywords: Harmonics, Series active filter, Passive filter, Hybrid power filter, Sinusoidal Fryze voltage control, Adaptive Tabu search algorithm.

\section{Introduction}

The compensation techniques applied in active and passive filters to eliminate current harmonics, voltage harmonics and to compensate reactive power have already been presented and published in the technical literature [1, 2, 3]. Shunt, series and hybrid active filter topologies have been conferred and demonstrated to be a feasible alternative for industrial compensation [5], [7]. Even though passive filters LC are most frequently used to compensate current harmonics, it is well recognized that they are not the most excellent solution, since they generate resonance problems, affect voltage regulation, and bring into being high inrush currents. Shunt active filter is a improved option for current harmonic and reactive power compensation; however its application in high power load compensation is still limited due to power semiconductors restrictions [2].

The series active power filter exertions as a voltage controlled source whereas the shunt active approach acts as a current controlled source. The series approach compensates for voltage distortion, unbalances, and regulation (sags and swells) [4]. Other well known topology is the hybrid filter [1], [7], [9], which uses a combination of active and passive filters, and is a good and successful alternative for current harmonics compensation. Now days, advance soft computing techniques are used widely in automatic control system or for optimization of the system applied. A few of them are such as adaptive tabu search [10]-[14], optimization of active power filter using Genetic algorithm[15]-[18], power loss minimization using particle swarm optimization[19], neural network control [20]-[24] applied in both machinery and filter devices.

This paper presents a dynamic compensation scheme that has been optimized using Adaptive tabu search algorithm enforced with a hybrid series active power filter, and is intended to compensate line current harmonics and reactive power generated by static converters.

The paper has been organized in the following manner. The APF configuration and the load under deliberation are discussed in Section II. The control algorithm for APF is discussed in Section III. Optimization using adaptive tabu search has been presented in Section IV. Comparative evaluation using MATLAB/Simulink results are discussed in Section V and finally Section VI concludes the paper.

Received: April $16^{\text {th }}$, 2013. Accepted: August $15^{\text {th }}, 2014$ 


\section{System Description}

As shown in Figure 1, Hybrid Series Power filter improves the power quality and compensates the harmonics within the system. The series active filter ideally behaves as a controlled voltage source in such some way that the load voltage will have solely positivesequence at the fundamental frequency component.

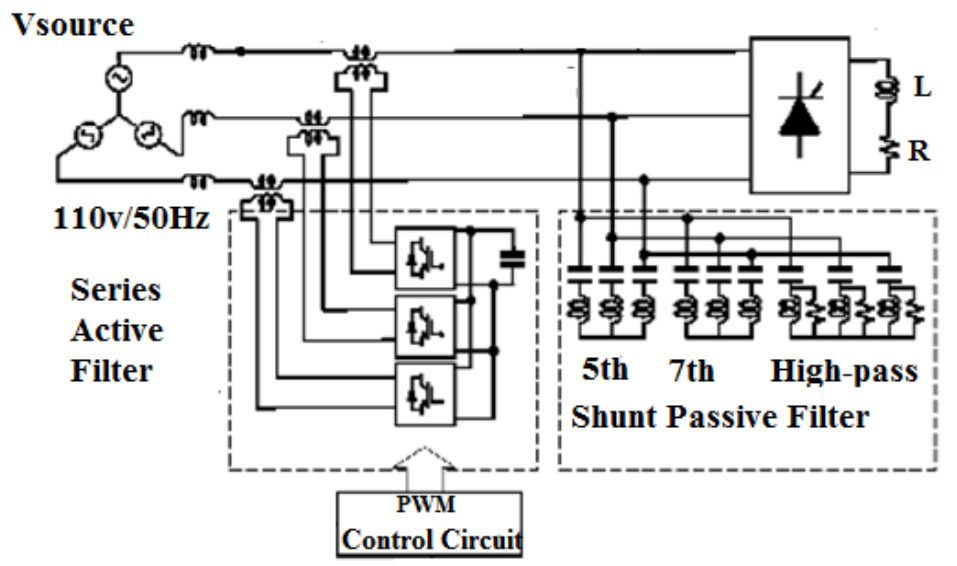

Figure 1. Hybrid Series Active Power filter

The voltages on the sources are given by $\mathrm{V}_{\mathrm{sa}}, \mathrm{V}_{\mathrm{sb}}$, and $\mathrm{V}_{\mathrm{sc}}$. Conversely, the relation among the supply voltage, the load voltage, and also the active filter voltage is given by

$$
\left[\begin{array}{c}
\mathrm{V}_{\mathrm{Sa}} \\
\mathrm{V}_{\mathrm{Sb}} \\
\mathrm{V}_{\mathrm{Sc}}
\end{array}\right]=\left[\begin{array}{c}
\mathrm{V}_{\mathrm{a}} \\
\mathrm{V}_{\mathrm{b}} \\
\mathrm{V}_{\mathrm{c}}
\end{array}\right]\left[\begin{array}{c}
\mathrm{V}_{\mathrm{Ca}} \\
\mathrm{V}_{\mathrm{Cb}} \\
\mathrm{V}_{\mathrm{Cc}}
\end{array}\right]
$$

The fundamental series active filter voltages are synthesized by three single-phase converters with a standard dc capacitor. The reference voltage for these converters is calculated by the "PWM Control circuit block that has active filter controller" shown in figure 1.

We know that thyristor rectifier shown behaves sort of a current source; the voltage source may be split into its fundamental voltage source and harmonic voltage source. The series active filter behaves just like the controlled voltage source $\dot{V}_{c}$ and also the shunt passive filter may be represented by equivalent impedance $\mathrm{z}_{\mathrm{F}}$. As per the fundamental compensation principle, the series active filter ought to synthesize the active impedance presenting zero impedance at the fundamental frequency and a high resistance $\mathrm{k}$ at the source or load harmonic frequencies.

The harmonic current running in the source is dependent on the both the load harmonic current $\dot{\mathrm{I}}_{\mathrm{Lh}}$ and the source harmonic voltage $\dot{\mathrm{V}}_{\mathrm{Sh}}$. $\mathrm{z}_{\mathrm{S}}$ presents the source impedance of the system.

It is given by

$$
\mathrm{i}_{\mathrm{sh}}=\frac{\mathrm{Z}_{\mathrm{F}}}{\mathrm{Z}_{\mathrm{F}}+\mathrm{Z}_{\mathrm{S}}+\mathrm{k}} \mathrm{I}_{\mathrm{Lh}}+\frac{\dot{\mathrm{V}}_{\mathrm{Sh}}}{\mathrm{Z}_{\mathrm{F}}+\mathrm{Z}_{\mathrm{s}}+\mathrm{k}}
$$

Where

$$
\mathrm{i}_{\mathrm{sh}} \cong 0 \quad \text { if } \quad \mathrm{k} \gg \mathrm{z}_{\mathrm{s},} \mathrm{z}_{\mathrm{F}}
$$

The output voltage of the series active filter is given by; 


$$
\begin{aligned}
& \dot{\mathrm{V}}_{\mathrm{c}}=\mathrm{k} \dot{\mathrm{I}}_{\mathrm{sh}}=\mathrm{k} \frac{\mathrm{z}_{\mathrm{f}} \dot{\mathrm{I}}_{\mathrm{Lh}}+\dot{\mathrm{V}}_{\mathrm{Sh}}}{\mathrm{z}_{\mathrm{F}}+\mathrm{Z}_{\mathrm{s}}+\mathrm{k}} \\
& \dot{\mathrm{V}}_{\mathrm{c}} \cong \mathrm{z}_{\mathrm{F}} \dot{\mathrm{I}}_{\mathrm{Lh}}+\dot{\mathrm{V}}_{\mathrm{sh}} \quad \text { if } \mathrm{k} \gg \mathrm{z}_{\mathrm{s},} \mathrm{z}_{\mathrm{F}}
\end{aligned}
$$

Equation (5) shows beyond any doubt that the voltage rating of the series active filter $\dot{V}_{c}$ is given by two factors; the primary term within the right hand side of the equation, which is reciprocally proportional to the shunt passive filter's quality factors, and also the second term are equal to the source harmonic voltage.

The harmonic voltage on the shunt passive filter is given by

$$
\begin{aligned}
& \dot{\mathrm{V}}_{\mathrm{Fh}}=\frac{\mathrm{z}_{\mathrm{s}}+\mathrm{k}}{\mathrm{z}_{\mathrm{F}}+\mathrm{Z}_{\mathrm{s}}+\mathrm{k}} \mathrm{Z}_{\mathrm{F}} \dot{\mathrm{I}}_{\mathrm{Lh}}+\frac{\mathrm{z}_{\mathrm{F}}}{\mathrm{z}_{\mathrm{F}}+\mathrm{Z}_{\mathrm{s}}+\mathrm{k}} \dot{\mathrm{V}}_{\mathrm{sh}} \\
& \dot{\mathrm{V}}_{\mathrm{Fh}} \cong-\mathrm{z}_{\mathrm{F}} \dot{\mathrm{I}}_{\mathrm{Lh}} \text { if } \mathrm{k} \gg \mathrm{z}_{\mathrm{s},} \mathrm{z}_{\mathrm{F}}
\end{aligned}
$$

The above equations show that by choosing $\mathrm{k}>>\mathrm{zS}, \mathrm{z}_{\mathrm{F}}$, no source harmonic voltage shows the shunt passive filter. Two harmonic current flows should be examined: one from the load to the source and the other from the source to the load.

\section{Control Theory}

The series active filter controller produces the reference voltage that will be synthesized by the PWM converter and positioned in series with the supply voltage, to force the load voltage, to become sinusoidal and balanced.

Based on Sinusoidal Fryze Voltages Control Strategy, the series active filter controller is composed by a circuit that senses the fundamental positive sequence component of the system voltage and generate compensating voltage references by performing the distinction between that fundamental component and the measured system voltages.

The blend of a shunt passive filter and a low-rated series active resulted in a very realistic and economical way to filter harmonic currents. The concept adopted in this approach differs from conventional shunt active filters or pure series active filters in terms of guaranteeing better filtering characteristics as well as lower initial costs. The required rating of the series active filter is mainly decided by the quality existing in the power system.

Though the quality factor of the shunt passive filter used in the experiments was equal to 14, it may be in the range of 50 to 80 in real cases. Therefore, the rated power of the series active filter may be as small as $1 \%$ of the rated power of the nonlinear load (thyristor rectifier or cycloconverter) if no background harmonic voltage lives in the source. This shows the way to the significant conclusion that this combined series active filter and shunt passive filter is one of the most suitable answers to high-power thyristor rectifiers, like those used in highvoltage dc transmission system (HVDC) or cycloconverters.

In this approach, the active filter is attached in series with the passive filter, as shown in figure 1.The composed branch of passive and active filters is connected in parallel, as closed as achievable to the harmonic-producing load. This new method provides hybrid filters which are somewhat different in circuit configuration; they are almost the same in operating principle and filtering performance. Such a mixture with the passive filter makes it possible to significantly reduce the rating of the active filter. Two passive filter tuned to compensate $5^{\text {th }} \& 7^{\text {th }}$ harmonics have been connected in parallel to series filter.

The function of the active filter is not to compensate for harmonic currents produced by the thyristor rectifier, but to achieve harmonic seclusion between the supply and the load. As a result, no harmonic resonance occurs, and harmonic current flows in the supply. 
In, this paper Adaptive Tabu Search algorithm has been applied to find out the optimum value of PI controller parameters used in Sinusoidal Fryze Voltage control strategy and make the system optimum.

\section{Optimization Using Adaptive Tabu Search Algorithm}

Adaptive Tabu Search (ATS) is a modified version of original tabu search formula for combinational optimization problem suggested by Glover. This technique is very useful for solving non-linear continuous optimization problems. The modification which has been added into the new version is discredited continuous search space, back-tracking and adaptive radius.

In this paper, the proposed ATS method searches the optimum value of the proportional integral controller parameters i.e. $\mathrm{K}_{\mathrm{p}}$ and $\mathrm{K}_{\mathrm{I}}$ and the objective function is decided such as to give their optimum value with the conditions of minimum overshoot, rise time and settling time. Boundary of $\mathrm{Kp}$ and $\mathrm{Ki}$, their upper limits and lower limits, then radius value, conditions for ATS back tracking, objective function and stop criteria has been defined. Maximum Searching iteration (500 rounds) for ATS has been set as stop criterion. Figure 2 shows the flow chart for search of parameters using adaptive tabu search method.

Since this paper is predicated on the critical analysis based on THD of the source it has been seen that the objective function taken has shown its effectiveness, which may be seen from the reduction of THD.

Computational time has conjointly been seen terribly less i.e. within seconds, all iterations are over and optimum values of $\mathrm{Kp}$ and $\mathrm{Ki}$ is seen on MATLAB/Simulink complier. We are able to see that this method is extremely stable, since it has been calculated offline so is accustomed replace the prevailing values. Strength of this algorithm can be understood by the nice results and less computational time. Convergence analysis has been done offline. Range of iterations with variation in $\mathrm{Kp}$ and $\mathrm{Ki}$ values has been taken to prove the pliability of the algorithm. This algorithm is extremely convenient to use due to the programming and fewer computational time. The practicability and advantage of the algorithm are verified by the simulation results. It is in no time. The parameters i.e. Kp and Ki has been set indiscriminately $\mathrm{ab}$ initio so it has been tuned by using this algorithm offline.

There has been a counter used, that will count the number of iterations and the program will stop automatically when count is equal to 500 i.e. stopping criteria is 500 iterations.

Objective function (O.F.) is defined by

$$
\begin{aligned}
& \text { O.F. }\left(T_{\text {Rise }}, T_{\text {Settling }}, \text { P.O. }\right)=A\left(T_{\text {Rise }}\right)+B\left(T_{\text {Settling }}\right)+C(\text { P.O. }) \\
& A+B+C=1
\end{aligned}
$$

P.O. is the percent overshoot.

$\mathrm{T}_{\text {Rise }}$ is the rise time.

$\mathrm{T}_{\text {Settling }}$ is the setting time.

A.B and $C$ are the priority coefficients of $\mathrm{T}_{\text {Rise }}, \mathrm{T}_{\text {Settling }}$, P.O. respectively.

In this paper, the values of $(\mathrm{A}, \mathrm{B}$, and $\mathrm{C}$ are set to $0.33,0.33$, and 0.34 , respectively. The ATS search can try and notice the most effective controller parameters to attain the minimum O.F. value.

Step 1: Tabu list and neighborhood list having values of $\mathrm{K}_{\mathrm{p}}$ and $\mathrm{K}_{\mathrm{i}}$ are loaded and counter has been set zero, which is able to check the number of iterations.

Step 2: value of the objective function has been calculated for initial values of $\mathrm{K}_{\mathrm{p}}$ and $\mathrm{K}_{\mathrm{i}}$.

Step 3: Resultant of step 2 has been compared from the Tabu list and if it is better than it's been compared from neighborhood list. If it's not better than Tabu list solutions, then these values are modified by varying the values of $\mathrm{K}_{\mathrm{p}}$ and $\mathrm{K}_{\mathrm{i}}$.

Step 4: If the results don't seem to be better than neighborhood list solutions, it will be saved in tabu list and so counter will automatically increased and there'll be variation in $\mathrm{K}_{\mathrm{p}}$ and $\mathrm{K}_{\mathrm{i}}$ value and these value will replace the previous value and again go to step 3 . 
Step 5: If the results are better than neighborhood list solutions, it'll be saved as best solution. Step 6: If variety of iteration i.e. count value is 500 , the results with the optimum value of $\mathrm{K}_{\mathrm{p}}$ and $K_{i}$ will be shown otherwise it'll check the counter value and vary the $K_{p}$ and $K_{i}$ values and go to step 3 .

It has been seen that the objective function actually based on percent overshoot, rise time and settling time, however the THD results outcome are excellent and since, since this paper will the assessment of the system based on THD of source, detail equations and values for percent overshoot, rise time and settling time haven't been given, only THD details have been mentioned.

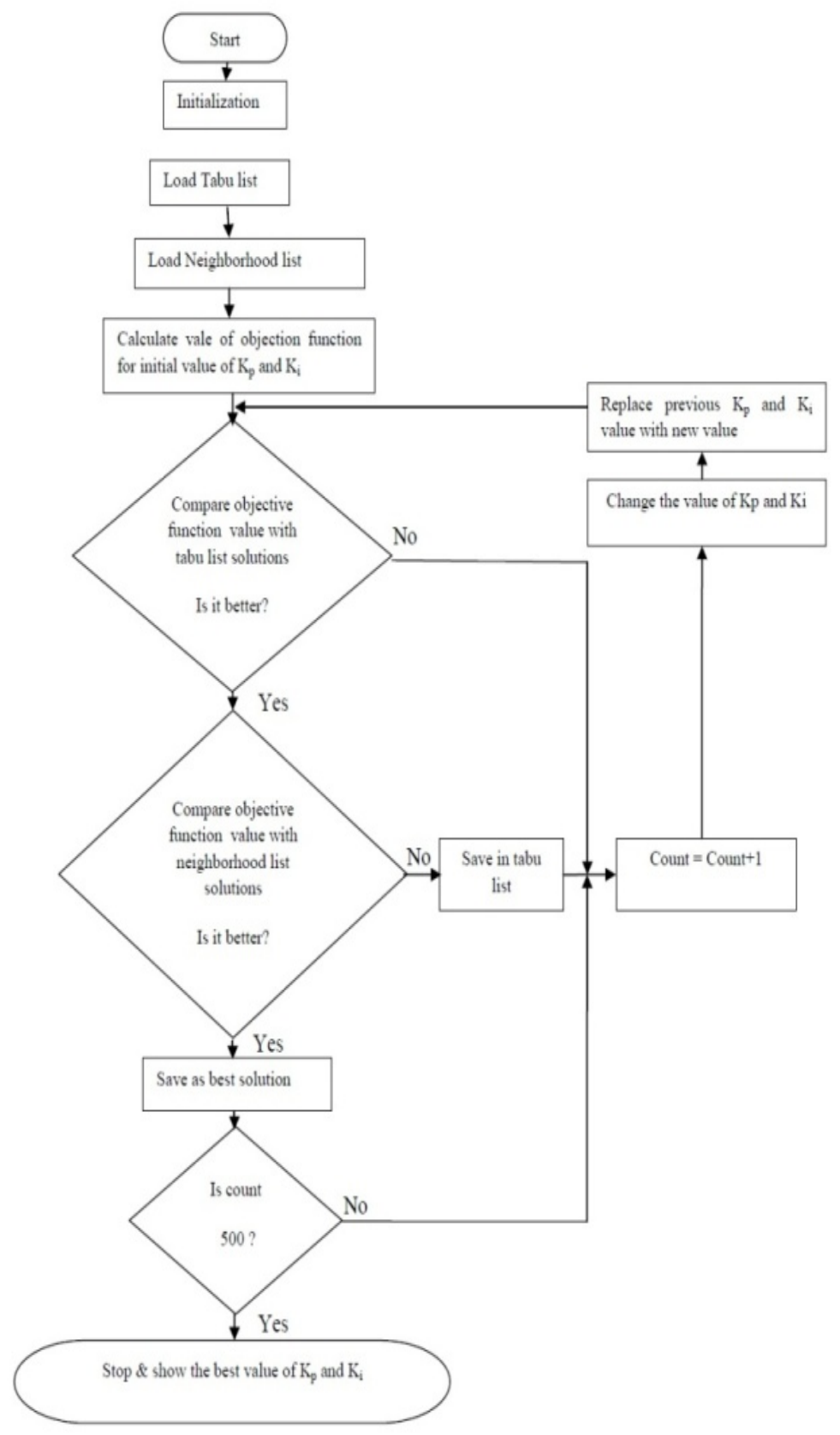

Figure 2. Flow chart for search of parameters using ATS 


\section{Comparative Evaluation Using Simulation Results}

The proposed scheme of Hybrid-Series Power filter (HPF) is simulated in MATLAB environment to estimate its performance. The load consists of a three-Phase diode bridge rectifier with R-L branch directly. The proposed control scheme has been simulated to calculate the performance of HPF and analysis through THD of source voltage and current. The simulation results clearly demonstrate that the scheme is able to successfully trim down the significant amount of THD in source voltage and current within limits of IEEE 519-1992. Simulation results have been analyzed on the basis of THD obtained. Simulation has been done for 15 cycles. Comparative evaluation of simulation using optimized SFV by ATS algorithm for series and hybrid power filter have been done.

\section{A. Uncompensated system}

After doing simulation in MATLAB/Simulink without using any filter (Figure 3) i.e. for Uncompensated System, it has been observed that the THD of source voltage found when load is connected with the system is $27.77 \%$. By observing these data, we can easily understand supply has been polluted when load has been connected.

\section{B. Performance of Series APF}

During the analysis of simulation results based on THD, this has been observed (Figure 3) that while doing simulation of Series power filter based on Sinusoidal Fryze Voltages Control Strategy that the THD of source Voltage were 2.34\%; whereas when model has been optimized using ATS algorithm has been used, it has been observed that the THD of source voltage reduces to $1.63 \%$ which is absolutely the improvement from conventional one. But it has been observed that THD for source current was more than specified limit in IEEE 519-1992 standard.

\section{Performance of Hybrid APF}

During the analysis of simulation results based on THD, this has been observed (Figure 4) that while doing simulation of Hybrid Series power filter optimized using ATS-SFV control has been used, it has been observed that the THD of source voltage reduces to $0.017 \%$ and THD of source current reduces to $0.013 \%$; which is absolutely the improvement from both the series filter results. It has also been observed that THD for source current was within the specified limit of IEEE 519-1992 standard. The only problem which has been observed that some unbalancing between the phases was there, which can be removed using a parallel RC branch of appropriate value. Table I presents the statistical view of THD response for different filter and schemes.

Table 1. Comparisons of THD for Different Schemes \& Filters

\begin{tabular}{|c|c|}
\hline Strategy Applied & THD-V (\%) \\
\hline $\begin{array}{ll}\begin{array}{l}\text { Sinusoidal Fryze Voltage control } \\
\text { (SFV) for series filter }\end{array} & \\
\end{array}$ & 2.34 \\
\hline ATS- SFV control for series filter & 1.63 \\
\hline ATS- SFV control for Hybrid filter & 0.017 \\
\hline
\end{tabular}


Performance Evaluation of Adaptive Tabu Search Algorithm Optimized Sinusoidal Fryze
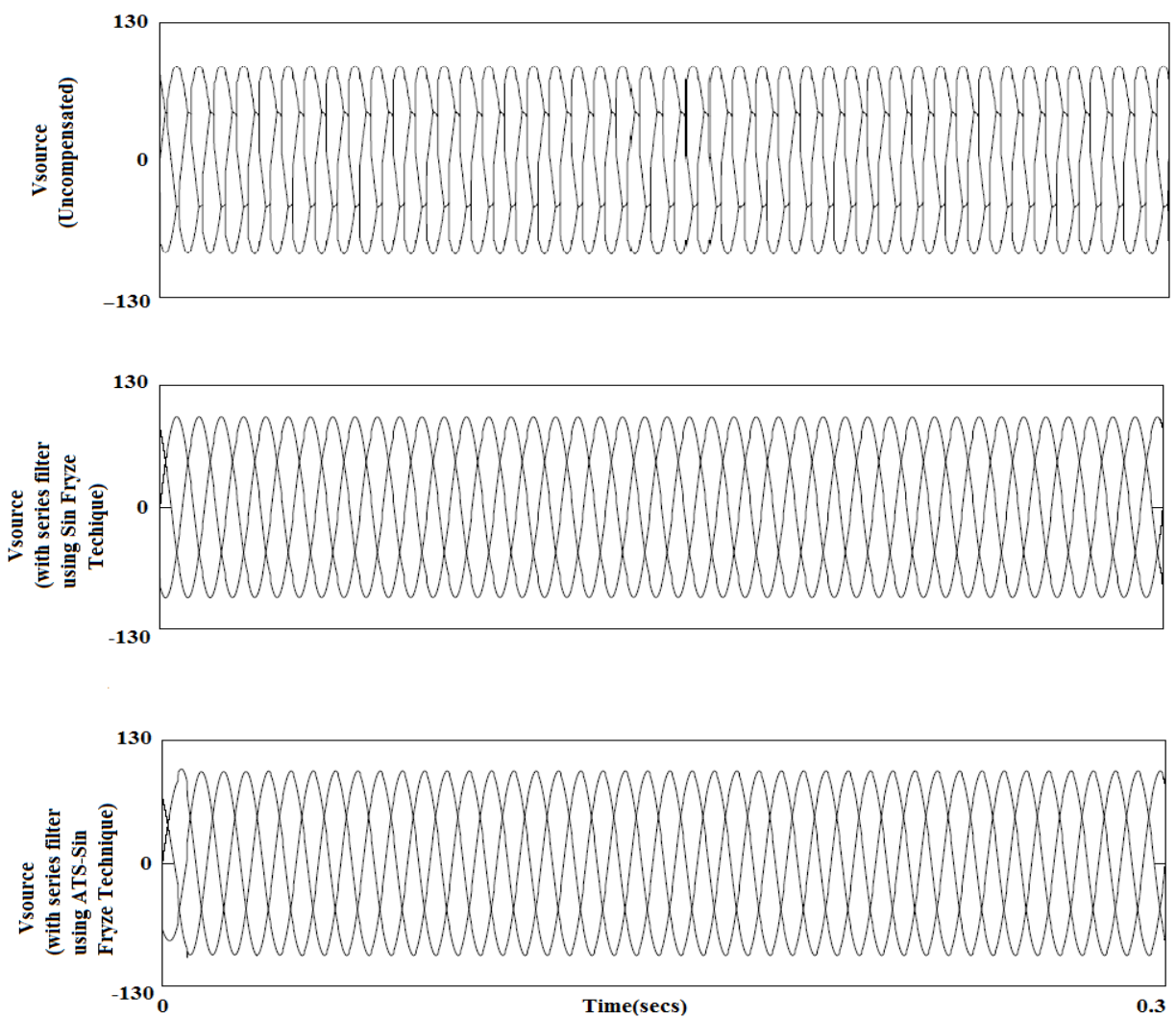

Figure 3. Source voltage waveforms of uncompensated system, using series filter utilizing Sin Fryze voltage technique and using series filter utilizing ATS- Sin Fryze voltage technique
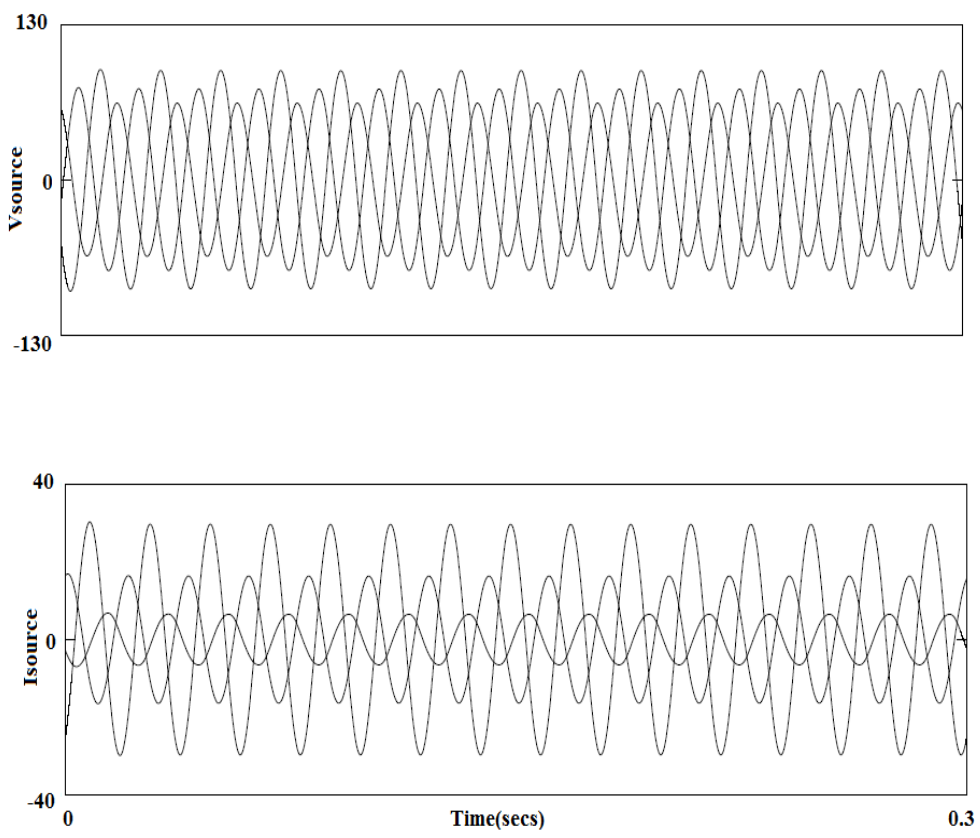

Figure 4. Waveforms of Source Voltage and source current for Hybrid power filter 
Figure 5 presents the comparative bar chart for THD-V for different control schemes. We can see that hybrid power filter is the best as comparison to other schemes.

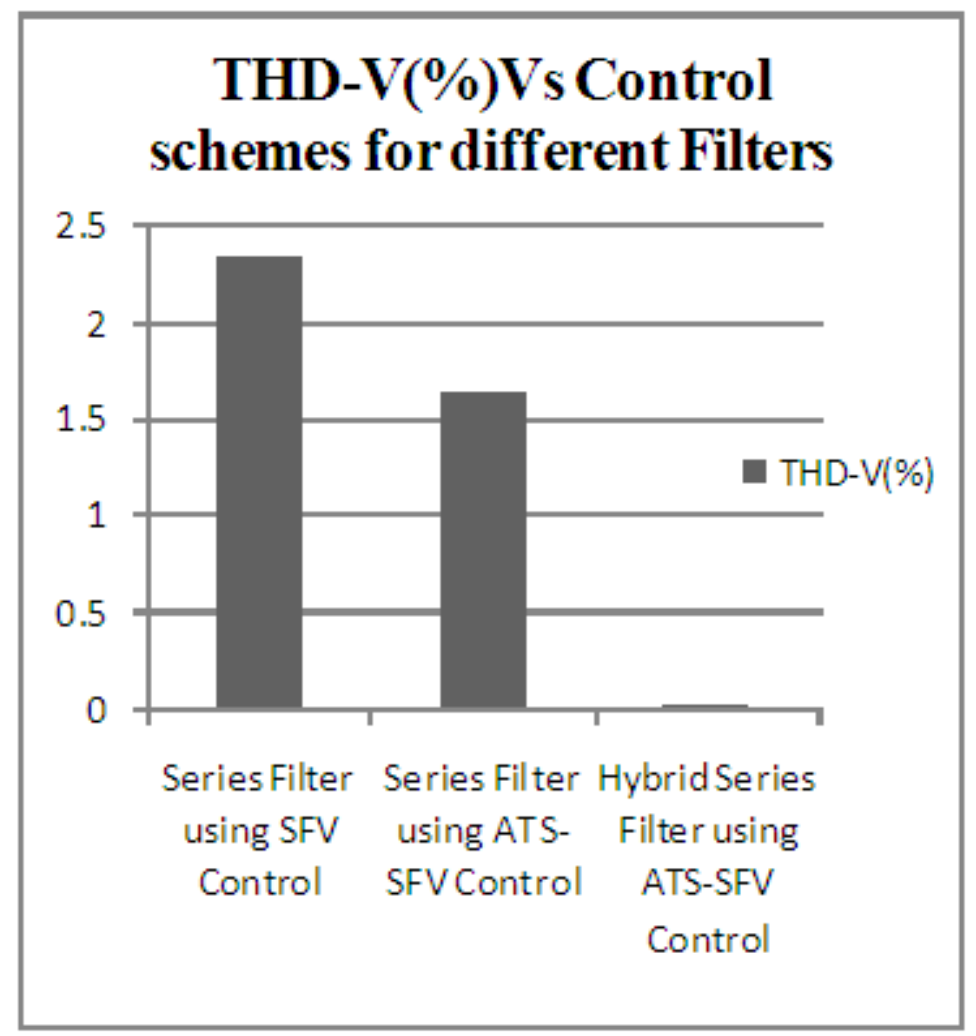

Figure 5. Comparative bar chart for THD-V(\%) between different control schemes

\section{Conclusion}

A novel ATS-Sin Fryze control technique for hybrid series power filter has been reported which clearly demonstrates its compensation ability. This also has been observed that adaptive tabu search algorithm has well optimized the model and increased the ability of conventional Sinusoidal Fryze Control model. From the simulation results of THD response, this can be easily seen that the proposed novel hybrid active filter is effective better than the series filter.

\section{References}

[1] H. Fujita, T. Yamasaki, and H. Akagi, “A Hybrid Active Filter for Damping of Harmonic Resonance in Industrial Power Systems”, IEEE Trans. on Power Electronics, Vol. 15, No. 2, March 2000.

[2] Rubén Inzunza and Hirofumi Akagi, “A 6.6-kV Transformer less Shunt Hybrid Active Filter for Installation on a Power Distribution System”, IEEE Trans. on Power Electronics, Vol. 20, No. 4, July 2005.

[3] Zhiguo Pan, Fang Z. Peng, and Suilin Wang, "Power Factor Correction Using a Series Active Filter”, IEEE Trans. on Power Electronic, Vol. 20, No. 1, January 2005.

[4] Abraham D. le Roux, Hendrik du T. Mouton, and Hirofumi Akagi, "Digital Control of an Integrated Series Active Filter and Diode Rectifier with Voltage regulation”, IEEE Trans. on Ind. Appl., Vol. 39, No. 6, Nov./Dec. 2003. 
[5] Luis A. Morán, Juan W. Dixon, Rogel R. Wallace, "A Three- Phase Active Power Filter Operating with Fixed Switching Frequency for Reactive Power and Current Harmonic Compensation”, IEEE Trans. on Ind. Electron, Vol. 42, No. 4, August 1995.

[6] Vijay B. Bhavaraju and Prasad N. Enjeti, "An Active line Conditioner to Balance Voltages in a Three-Phase System”, IEEE Trans. on Ind. Appl., Vol. 32, No. 2, March./April 1996.

[7] Sangsun Kim and Prasad N. Enjeti, "A New Hybrid Active Power Filter (APF) Topology”, IEEE Trans. on Power Electronics, Vol.17, No. 1, January 2002.

[8] P. Ruminot, L. Morán, E. Aeloiza, P. Enjeti and J. Dixon, “A New Compensation Method for High Current Non-Linear Loads” Industrial Electronics_ 2006 IEEE International Symposium on. Vol. 2, pp 1480-1485, July 2006.

[9] A. D. le Roux, H. D. T. Mouton, H. Akagi. "Digital Control of an integrated series active filter and passive rectifier with voltage regulation" Proceedings of the Power Conversion Conference, Vol 1, pp 68-73, 2002.

[10] T. Sopapirm, K-N.Areerak, K-L.Areerak, A.Srikaew, "The Application of Adaptive Tabu Search Algorithm and Averaging Model to the Optimal Controller Design of Buck Converters”, World Academy of Science, Engineering and Technology, Volume 60, pp. 477-483, 2011.

[11] K. Chaijarurnudomrung, K-N. Areerak, K-L. Areerak, and A.Srikaew, "The Controller Design of Three-Phase Controlled Rectifier Using an Adaptive Tabu Search Algorithm, Proceedings of 8th Electrical Engineering/ Electronics, Computer, Telecommunications and Information Technology (ECTI), Thailand, 2011, pp.605- 608.

[12] Niraj Kumar, Khem B. Thapa and S.Khalid, "A Novel Series Active Power Filter Scheme using Adaptive Tabu search Algorithm for Harmonic Compensation,” International Journal of Application or Innovation in Engineering \& Management (IJAIEM), Vol. 2, Issue 2, pp. 155-159, Feb 2013.

[13] S. Khalid, Anurag Tripathi, " Simulation of Shunt Active Filters based on Sinusoidal Current Control Strategy in High Frequency Aircraft System," International Journal of Management, IT and Engineering, Vol. 3, Issue 1, pp. 218-230, January 2013.

[14] Saifullah Khalid, Bharti Dwivedi, Bhim Singh, “ New Optimum Three-Phase Shunt Active Power Filter based on Adaptive Tabu Search and Genetic Algorithm using ANN control in unbalanced and distorted supply conditions,” Elektrika : Journal of Electrical Engineering, Vol. 14, Issue 2, pp. 09-14, 2012.

[15] Babak Keshavarz Hedayati, Abdolreza Rahmati, "Genetic Algorithm Application in Controlling Performance and Power Dissipation of Active Power Filters", Canadian Journal on Electrical \& Electronics Engineering, Vol. 1, No. 1, pp. 15-19, February 2010.

[16] Parmod Kumar, and Alka Mahajan, "Soft Computing Techniques for the Control of an Active Power Filter”, IEEE Transactions on Power Delivery, Vol. 24, No. 1, pp. 452-461, January 2009.

[17] Marco Liserre, Antonio Dell Aquila, and Frede Blaabjerg, "Genetic Algorithm-Based Design of the Active Damping for an LCL-Filter Three-Phase Active Rectifier", IEEE Transactions on Power Electronics, Vol. 19, No. 1, pp.76-86, January 2004.

[18] M. El-Habrouk and M. K. Darwish, "A New Control Technique for Active Power Filters Using a Combined Genetic Algorithm/Conventional Analysis”, IEEE transactions on Industrial Electronics, Vol. 49, No. 1, pp. 58-66, February 2002.

[19] Radha Thangaraj, Thanga Raj Chelliah, Millie Pant, Ajit Abraham and Crina Grosan, "Optimal gain tuning of PI speed controller in induction motor drives using particle swarm optimization,” Logic Journal of IGPL Advance Access, pp.1-14, July 2010.

[20] Avik Bhattacharya, Chandan Chakraborty, "A Shunt Active Power Filter With Enhanced Performance Using ANN-Based Predictive and Adaptive Controllers," IEEE Transactions on Industrial Electronics, Vol. 58, No. 2, pp. 421-428, February 2011. 
[21] Whei-Min Lin, Chih-Ming Hong, "A New Elman Neural Network-Based Control Algorithm for Adjustable-Pitch Variable-Speed Wind-Energy Conversion Systems," IEEE Transactions on Power Electronics, Vol. 26, No. 2, pp. 473-481, February 2011.

[22] Jiang You-Hua, Chen Yong-Wei, "Neural Network Control Techniques of Hybrid Active Power Filter," Proceedings of International Conference on Artificial Intelligence and Computational Intelligence, 2009, pp. 26-30.

[23] Bhim Singh,Vishal Verma, and Jitendra Solanki, "Neural Network-Based Selective Compensation of Current Quality Problems in Distribution System”, IEEE Transactions on Industrial Electronics, Vol. 54, No. 1, February 2007, 53-60.

[24] R. Dehini, A. Bassou, B. Ferdi, "Artificial Neural Networks Application to Improve Shunt Active Power Filter," International Journal of Computer and Information Engineering, Vol. 3, No. 4, pp. 247-254, 2009.

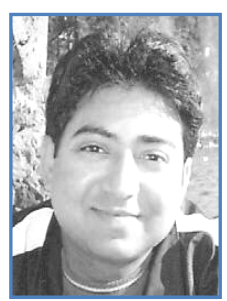

Saifullah Khalid born in India. He received his B.E. degree in Electronics \& Telecommunication Engineering from S.E.S.C.O.E., Dhule in 2001, M.Tech Degree in Electrical Engineering from the M.M.M.E.C., Gorakhpur, in 2003 respectively. He is presently pursuing his Ph.D. in Electrical Engineering from U.P. Technical University Lucknow, India. He worked as faculty in various engineering colleges from 2003 to 2008 . He has been author/coauthor of more than 50 papers and 04 books. In 2008, he joined Airports Authority of India, India as Air Traffic Control Officer. His current research interests include aircraft system, artificial intelligent technique and their applications in power quality. He is a member of the IEEE, IAENG, IACSIT and the Cleveland engineering society.

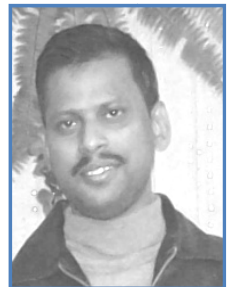

Niraj Kumar born in India. Obtained his bachelor's degree in Electronics \& Communication Engineering from 2003 respectively. He is presently working as Reader in Electronics \& Communication Engineering Department of U.I.E.T. (Kanpur University). He has been author/coauthor of more than 10 papers and 02 books. His current research interests include power filter, artificial intelligent technique and their applications in power quality. He is a member of the IETE. He has been author/coauthor of more than 10 papers and 02 books. His current research interests include power filter, artificial intelligent technique and their applications in power quality. He is a member of the IETE.

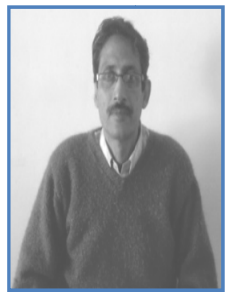

V. M. Mishra born in India. He received B.E. Degree from MMM Engineering College Gorakhpur, India in 1988, M.Tech from Regional Engineering College, Kurushetra, India in 1995, and pursuing Ph.D degree from the UP Technical University Lucknow, India, all in electrical engineering. In 2005 he joined G B Pant Engg College Pauri Garhwal. Before 2005, he was working in MMM Engg College Gorakhpur. His main area of interest includes power electronics control, power quality applications, active power filters, electrical drives and wind energy conversion systems. 